\title{
Energy intake in short bowel syndrome: assessment by 24-h dietary recalls compared with the doubly labelled water method
}

\author{
Priscila G. Fassini ${ }^{1 *}$, Sai Krupa Das ${ }^{2}$, Karina Pfrimer $^{1}$, Vivian M. M. Suen ${ }^{1}$, Júlio Sérgio Marchini ${ }^{1}$ \\ and Eduardo Ferriolli ${ }^{1}$ \\ ${ }^{1}$ Department of Internal Medicine, Ribeirão Preto Medical School, University of São Paulo, Ribeirão Preto, SP, Brazil \\ ${ }^{2}$ Energy Metabolism Laboratory, Jean Mayer USDA Human Nutrition Center on Aging, Tufts University, Boston, MA, USA
}

(Submitted 28 June 2017 - Final revision received 11 October 2017 - Accepted 2 November 2017 - First published online 22 December 2017)

\section{Abstract}

Short bowel syndrome (SBS) represents a serious intestinal absorption disorder, and patients may be prone to severe malnutrition. Dietetic therapy is critically important both for immediate prognosis and successful long-term rehabilitation. To maintain energy balance, an accurate assessment of energy intake is required. Our objective was to compare energy intake (EI) assessed by 24-h dietary recalls (EIrecall), a standard clinical assessment, with the total energy expenditure measured by the doubly labelled water (TEEdlw) method in SBS patients and matched controls. A total of twenty-two participants (eleven each in the SBS and control groups (CG), six female and five male) were evaluated; CG were matched to SBS patients on the basis of age, BMI and sex. TEE was measured by DLW and compared with EI determined by four 24-h dietary recalls using the USDA Automated Multiple-Pass Method. Bland-Altman plots and paired Student's $t$ test were used to compare EIrecall with TEEdlw $(P<0.05$ ). Participants' mean age was 53 (sD 8 ) years. TEEdlw (7.85 (sD $1 \cdot 16$ ) MJ/d, 0.14 (sD 0.02) MJ/kg per d) was significantly lower $(P=0.014)$ compared with EIrecall $(11.07$ (sD 3.45) MJ/d, 0.21 (sD 0.08) MJ/kg per d) in the SBS group. On the other hand, in the CG group TEEdlw (10.02 (sD 1.86) MJ/d, 0.18 (sD 0.03) MJ/kg per d) was significantly higher $(P=0.001)$ compared with EIrecall (7.19 (sD 1.68 ) $\mathrm{MJ} / \mathrm{d}, 0.13$ (sD 0.03) MJ/kg per d). In SBS patients, reported EI is higher than DLW-measured EI. Therefore, providing or prescribing energetic intake based on EIrecall without accounting for potential malabsorption-related losses can compromise the energy needs in SBS patients and affect nutritional status in the long term.

\section{Key words: Short bowel syndrome: Doubly labelled water: Total energy expenditure: Energy intake}

Short bowel syndrome (SBS) is a type of intestinal failure caused by intestinal resection resulting in a shortened intestinal remnant $^{(1)}$. SBS represents a serious malabsorption disorder, the dietetic management of which is extremely challenging ${ }^{(2)}$. SBS is characterised by an inability to maintain protein-energy, fluid, electrolyte or micronutrient balances when patients are on a conventional $\operatorname{diet}^{(1,3)}$.

Although it is considered rare, the true incidence and prevalence of SBS in adults is unknown because of the lack of precise definitions ${ }^{(3)}$ for this disorder. In the USA, the estimated annual prevalence of SBS in patients with non-malignant bowel disease requiring home parenteral nutrition (PN) is at least four per hundred thousand ${ }^{(4)}$.

The treatment of patients with SBS is complex since these patients are heterogeneous both conditions leading up to the SBS and in the clinical manifestation of their symptoms. Therefore, nutritional therapy needs to be individualised and depends on the gastrointestinal anatomy, length and health of the remaining intestine ${ }^{(5,6)}$. Commonly, SBS is associated with complications such as diarrhoea, dehydration, weight loss and nutritional deficiencies ${ }^{(6,7)}$. Weight loss results from failure to meet the body's energy needs, and complications associated with nutritional support usually determine the morbidity and mortality of these patients ${ }^{(8)}$. Therefore, it is important to accurately assess the energy intake (EI) of these patients and provide adequate nutrients to compensate for the malabsorption and symptom-related energy losses.

Assessments of dietary intake in a clinical setup is most easily achieved by collecting self-reported data using a variety of methods such as diet histories, 24-h dietary recalls, food frequency questionnaires and weighed-food records. However, self-reported intake may not accurately reflect actual energy requirements $^{(9)}$, and data in SBS patients are lacking ${ }^{(2)}$. Energy requirements can be measured in weight-stable, free-living individuals using the doubly labelled water (DLW) technique. However, this method is highly specialised and requires a high

Abbreviations: CG, control group; DLW, doubly labelled water; EI, energy intake; EIrecall, self-reported 24-h energy intake; PN, parenteral nutrition; REE, resting energy expenditure; SBS, short bowel syndrome; TEE, total energy expenditure; TEEdlw, TEE measured by the DLW.

* Corresponding author: P. G. Fassini, email priscilafassini@usp.br 
cost, which limits its use in clinical practice ${ }^{(10)}$. Estimating the energy gap between self-reported and measured energy expenditure is greatly useful for the purpose of planning energy needs for dietetic management and to correct for energy lost in malabsorption, thus ensuring that energy requirements are adequate to prevent malnutrition in SBS patients.

This aim of this study was to compare the accuracy of EI assessed by 24-h dietary recalls (EIrecall) with the total energy expenditure (TEE) measured by the DLW method (TEEdlw) in SBS patients in comparison with matched controls.

\section{Methods \\ Patient selection}

This observational study included participants with SBS (SBS group) and a matched control group (CG). Each CG patient was free from SBS but was matched for age, sex, ethnicity, BMI and chronic disease conditions similar to the SBS patient.

SBS participants were recruited from the Metabolic Unit and Ambulatory Nutrition Unit of the University Hospital at the Ribeirão Preto Medical School. Most SBS patients presented an intestinal transit time of $15 \mathrm{~min}$ and history of large intestinal resection $^{(11)}$.

Matched controls (CG) were selected by extensive evaluation of electronic medical records at the University Hospital, and via advertisements using the web (University intranet and internet), radio and television.

This study was approved by the Ethics Committee of the Ribeirão Preto Medical School, São Paulo University (process no. 1822/2013), and conducted according to the Helsinki Declaration. This trial was registered at clinicaltrials.gov as NCT02113228.

\section{Anthropometric measurements}

Weight was measured after an overnight fast and after participants emptied their bladder, using an electronic scale (Filizola) with the participant on barefeet and wearing a hospital gown. Height was obtained by using a wall-mounted stadiometer (Filizola). BMI was classified according to the World Health Organization $^{(12)}$.

\section{Resting energy expenditure and macronutrient oxidation rate}

Resting energy expenditure (REE) and macronutrient oxidation rate was assessed by indirect calorimetry (IC) using the Quark $\mathrm{RMR}^{\circledR}$ calorimeter (Cosmed). The IC test was conducted in the morning after $12 \mathrm{~h}$ of fasting. Participants were asked to rest quietly in a temperature-controlled room for $30 \mathrm{~min}$ before beginning the test. Measurements were collected for $30 \mathrm{~min}$ using a canopy with hood using standard practices ${ }^{(13,14)}$, as outlined in our previous publication ${ }^{(2)}$. The first 5 min of data were excluded from analyses. Weir's formula ${ }^{(15)}$ was used to calculate REE and Frayn's formula ${ }^{(16)}$ to calculate carbohydrate and lipid oxidation from $\mathrm{VO}_{2}$ and $\mathrm{VCO}_{2}$.

RQ was calculated using the ratio of the volume of carbon dioxide expired $\left(\mathrm{VCO}_{2}\right)$ to the volume of $\mathrm{O}_{2}$ inspired $\left(\mathrm{VO}_{2}\right)$.

\section{Total energy expenditure}

As in our previous publication ${ }^{(2)}$, TEE was measured by the DLW using the multi-point method over $14 \mathrm{~d}^{(17)}$. A baseline urine sample was collected before the participant received the DLW dose $\left({ }^{2} \mathrm{H}_{2}^{18} \mathrm{O}\right.$ ) (2g of $10 \% 18 \mathrm{O}-$ labelled and $0.12 \mathrm{~g}$ of $99.9 \%$ ${ }^{2} \mathrm{H}$-labelled water/kg estimated total body water). The deuterium oxide and ${ }^{18} \mathrm{O}$ were supplied by Sercon Ltd. Urine samples were collected daily over the $14 \mathrm{~d}$ to enhance adherence and minimise confusion regarding the 'days to collect'; however, only the urine samples from days 1, 2, 3, 7, 12, 13 and 14 were used in the analyses ${ }^{(2)}$. Measurement of $\mathrm{H}$ and $\mathrm{O}_{2}$ isotope enrichments were analysed using the isotope ratio MS (Hydra System, ANCA 20-22; Sercon or Europa Scientific) at the Mass Spectrometry Laboratory from Ribeirão Preto Medical School. TEEdlw was calculated using the recommendations of the International Dietary Energy Consultancy Group (IDECG) working group ${ }^{(17)}$, by the method described by Coward ${ }^{(18)}$ using the value of 0.85 for $\mathrm{RQ}^{(19)}$.

\section{Body composition}

Body composition was determined using the ${ }^{2} \mathrm{H}$ dilution technique measures as part of the DLW studies and using the total body water measurements from which fat-free mass and fat mass were calculated ${ }^{(20)}$. For the purposes of DLW dosing, total body water was calculated ${ }^{(17,20)}$.

\section{Assessment of energy and macronutrient intake}

EIrecall was assessed by four 24-h dietary recalls (three on weekdays, and one on the weekend) applied to participants, following the recommendations of the US Department of Agriculture Automated Multiple-Pass Method $^{(21)}$. Three 24-h dietary recalls during the weekdays were collected by a trained dietitian, using a picture booklet to improve the quality of the information provided on portion size ${ }^{(22)}$. One 24-h dietary recall, for the weekend days, was collected by telephone, as results obtained through a telephone interview are similar to the results obtained in person ${ }^{(23)}$ and as this was the only way it was feasible to collect a weekend recall.

A protocol was followed for the standardisation of home measures, where a table to estimate food consumption using home measures ${ }^{(24)}$ and a picture booklet ${ }^{(22)}$ were used to convert the food to $\mathrm{g}$ or $\mathrm{ml}$. The PN was considered to calculate energy and macronutrients for the SBS patients for the week that they received the PN at Metabolic Unit in the hospital.

The software Virtual Nutri Plus ${ }^{\circledR}$ updated with data from the Brazilian Food Composition Table ${ }^{(25)}$ and the USDA American Table ${ }^{(26)}$ was used to calculate energy and macronutrient intakes. For dietary intake analyses, an adjustment of energy and macronutrient data by intrapersonal and interpersonal variability (attenuation method) was applied in order to reduce the distortion of consumption estimates and, consequently, increase the reliability of the results obtained. In this method, a semi-parametric transformation approach was used to estimate usual daily intake distributions according to the method from Iowa State University ${ }^{(27)}$, using the software PC-Side 1.0 version (Iowa State University).

Macronutrient intake was assessed using the following recommendations: $45-65 \%$ of the total energetic value of the 
diet from carbohydrate, $10-35 \%$ from proteins and $20-35 \%$ from lipids (Acceptable Macronutrient Distribution Ranges) ${ }^{(28)}$.

Misreporting was determined as described by Black \& Cole ${ }^{(29)}$.

\section{Statistical analysis}

The sample size was not calculated once we included all the SBS patients registered at our hospital during the past eighteen years. Given that SBS is a rare disease, we would not have been able to increase our sample size, and the current pool is fairly representative of this population.

Results are shown as means and standard deviations. Kolmogorov-Smirnov test was used to assess the normality of the data and independent Student's $t$ test to compare the SBS patients with the subjects in the CG. Bland-Altman plots were used to compare EIrecall with TEEdlw in each group.

The significance level considered for the tests was set at $P<0 \cdot 05$. All analyses were performed by using SPSS version 21.0.

\section{Results}

\section{Participant characteristics}

A total of twenty-two participants, eleven each in the SBS and CG groups (five men and six women), aged 53 (SD 8) years (range: $37-65$ years) were evaluated. The average time since surgery was 8.2 (SD 5.6) years (range: $1-18$ years). The clinical information pertaining to the SBS participants, in particular the aetiology, the amount of surgical resection and amount of bowel remaining and intestinal transit time, are provided in Table 1. All patients with SBS had an intestinal transit time of $<30 \mathrm{~min}$, and most of them presented a remaining intestine with $<120 \mathrm{~cm}$.

Nine SBS patients were from the Ambulatory Nutrition Unit of the University Hospital at the Ribeirão Preto Medical School, and two patients were from the Metabolic Unit and were on partial PN only for 1 week (energy needs were supported with PN and oral intake, which required them to be inpatients) during the 2-week study period. Nutritional status was monitored by the hospital staff for all SBS patients who also received oral supplements of vitamins and/or electrolytes based on their individual needs.

\section{Anthropometric characteristics and body composition}

The anthropometric characteristics, body composition and phase angle of the patients are described in Table 2 . There were no significant differences between groups. All patients presented stable weight and BMI during the year before and during their participation in this research.

\section{Resting energy expenditure, macronutrient oxidation rate and total energy expenditure}

TEE, REE, macronutrient oxidation rate and RQ of the groups are shown in Table 3.

TEEdlw was significantly lower $(P<0.01)$ in the SBS group (7.85 (sD 1.16) $\mathrm{MJ} / \mathrm{d}$, range: 6.18-9.49 $\mathrm{MJ} / \mathrm{d}$; equivalent, on average, to $0 \cdot 14 \mathrm{MJ} / \mathrm{kg}$ per $\mathrm{d}$ ), compared with the CG group (10.02 (sD 1.86) $\mathrm{MJ} / \mathrm{d}$, range: 7.9-12.98 MJ/d; equivalent, on average, to $0 \cdot 18 \mathrm{MJ} / \mathrm{kg}$ per $\mathrm{d}$ ).

REE did not differ significantly between the groups when measured by IC $(5.68$ (SD 0.79) $\mathrm{MJ} / \mathrm{d}$, range: $4.44-7.05 \mathrm{MJ} / \mathrm{d}$, for the SBS group) $(5 \cdot 73$ (sD $0 \cdot 82) \mathrm{MJ} / \mathrm{d}$, range: $4 \cdot 6-7 \cdot 14 \mathrm{MJ} / \mathrm{d}$ for the CG group); the RQ and the oxidation rate of carbohydrates and lipids also did not differ significantly between the SBS and CG.

Table 2. Anthropometric characteristics of the groups* (Mean values and standard deviations)

\begin{tabular}{lcccccc}
\hline & \multicolumn{2}{c}{ SBS $(n$ 11) } & & \multicolumn{2}{c}{ CG $(n$ 11) } & \\
\cline { 2 - 3 } & Mean & SD & & Mean & SD & $P †$ \\
\hline Weight $(\mathrm{kg})$ & 55.7 & 8.7 & 57.6 & 6.6 & 0.56 \\
Height $(\mathrm{cm})$ & 161 & 8 & & 161 & 7 & 0.95 \\
BMl $\left(\mathrm{kg} / \mathrm{m}^{2}\right)$ & 21.5 & 3.4 & & 22.3 & 2.5 & 0.54 \\
Water $(\mathrm{kg})$ & 29.1 & 4.3 & & 29.7 & 5.0 & 0.79 \\
Lean body mass $(\mathrm{kg})$ & 39.9 & 5.9 & & 40.7 & 6.9 & 0.79 \\
Fat $(\mathrm{kg})$ & 15.7 & 5.4 & & 17.0 & 5.0 & 0.58 \\
Fat $(\%)$ & 27.8 & 7.8 & & 29.5 & 8.5 & 0.62 \\
\hline
\end{tabular}

SBS, short bowel syndrome; CG, control group.

* Participants without SBS (CG) were matched for characteristics similar to those of SBS participants including sex, age, ethnicity, BMI and chronic diseases. The body composition was determined using the ${ }^{2} \mathrm{H}$ dilution technique measures as part of the doubly labelled water method.

$\dagger$ Independent Student's $t$ test for comparison between SBS and CG groups.

Table 1. Baseline characteristics of short bowel syndrome participants*

\begin{tabular}{|c|c|c|c|c|}
\hline Participants & Resection aetiology & Remaining intestine or intestinal resection & $\begin{array}{l}\text { lleocecal } \\
\text { valve }\end{array}$ & $\begin{array}{l}\text { Intestinal transit } \\
\text { time (min) }\end{array}$ \\
\hline 1 & Crohn's disease & $\begin{array}{l}\text { Resection of a segment of the jejunum and ileum and partial } \\
\text { resection of the colon }\end{array}$ & No information & 15 \\
\hline 2 & Mesenteric thrombosis & Remaining intestine: $30 \mathrm{~cm}$ of small bowel and $40 \mathrm{~cm}$ of the colon & Absent & 15 \\
\hline 3 & Mesenteric thrombosis & Remaining intestine: $30 \mathrm{~cm}$ of the jejunum and $90 \mathrm{~cm}$ of the ileum & Present & 20 \\
\hline 4 & Mesenteric ischaemia & Remaining intestine: $45 \mathrm{~cm}$ of small bowel and colon & Present & 15 \\
\hline 5 & Crohn's disease & Remaining intestine: $60 \mathrm{~cm}$ of the jejunum & Absent & 30 \\
\hline 6 & Mesenteric thrombosis & Remaining intestine: $25 \mathrm{~cm}$ of the jejunum and transverse colon & Absent & 15 \\
\hline 7 & Mesenteric thrombosis & Extensive resection of the small bowel and colon & Present & 15 \\
\hline 8 & Mesenteric thrombosis & Remaining intestine: $40 \mathrm{~cm}$ of the jejunum and transverse colon & Absent & 15 \\
\hline 9 & Mesenteric ischaemia & Remaining intestine: $70 \mathrm{~cm}$ of the jejunum & Absent & 5 \\
\hline 10 & Mesenteric thrombosis & Remaining intestine: part of the jejunum and colon & Present & 15 \\
\hline 11 & Crohn's disease & Remaining intestine: $90 \mathrm{~cm}$ of small bowel and $10 \mathrm{~cm}$ of colon & Absent & 15 \\
\hline
\end{tabular}

* Clinical information of participants with short bowel syndrome were obtained from the medical records. 


\section{Assessment of energy and macronutrient intake}

The assessment of energy and macronutrient intake is shown in Table 4. EIrecall adjusted for intrapersonal and interpersonal variability showed that the energetic intake was significantly higher $(P<0.05)$ in the patients in the SBS group compared with the CG.

Table 3. Energy expenditure and substrate oxidation rate of the groups* (Mean values and standard deviations)

\begin{tabular}{|c|c|c|c|c|c|}
\hline & \multicolumn{2}{|c|}{ SBS $(n 11)$} & \multicolumn{2}{|c|}{$\mathrm{CG}(n 11)$} & \multirow[b]{2}{*}{$P \dagger$} \\
\hline & Mean & SD & Mean & SD & \\
\hline $\begin{array}{l}\text { REE indirect calorimetry } \\
(\mathrm{MJ} / \mathrm{d})\end{array}$ & $5 \cdot 68$ & 0.79 & 5.73 & 0.82 & 0.85 \\
\hline Carbohydrate oxidation (g/d) & 55.4 & $64 \cdot 6$ & 64.8 & $81 \cdot 6$ & 0.77 \\
\hline Lipid oxidation (g/d) & $120 \cdot 5$ & $34 \cdot 4$ & $119 \cdot 1$ & $38 \cdot 2$ & 0.93 \\
\hline $\mathrm{RQ}$ & 0.75 & 0.06 & 0.76 & 0.07 & 0.78 \\
\hline TEE DLW (MJ/d) & 7.85 & $1 \cdot 16$ & $10 \cdot 02$ & 1.86 & 0.004 \\
\hline $\mathrm{MJ} / \mathrm{kg}$ of body weight (DLW) & 0.14 & 0.01 & 0.18 & 0.03 & 0.004 \\
\hline
\end{tabular}

SBS, short bowel syndrome; CG, control group; REE, resting energy expenditure; TEE, total energy expenditure; DLW, doubly labelled water.

* Participants without SBS (CG) were matched for characteristics similar to those of SBS participants including sex, age, ethnicity, BMI and chronic diseases.

† Independent Student's $t$ test for comparison between SBS and CG groups.

Table 4. Self-reported 24-h energy intake (Elrecall) and macronutrient composition of the diet of the groups*

(Mean values and standard deviations)

\begin{tabular}{|c|c|c|c|c|c|}
\hline & \multicolumn{2}{|c|}{ SBS $(n 11)$} & \multicolumn{2}{|c|}{$\mathrm{CG}(n 11)$} & \multirow[b]{2}{*}{$P \dagger$} \\
\hline & Mean & SD & Mean & SD & \\
\hline Elrecall $(\mathrm{MJ} / \mathrm{d})$ & 11.07 & 3.45 & $7 \cdot 19$ & 1.68 & 0.00 \\
\hline $\mathrm{MJ} / \mathrm{kg}$ of body weight & 0.21 & 0.08 & 0.13 & 0.03 & 0.005 \\
\hline Carbohydrate $(\mathrm{g} / \mathrm{d})$ & 369 & 161 & 213 & 73 & 0.00 \\
\hline Carbohydrate (\% DV) & 54 & 8 & 49 & 6 & 0.097 \\
\hline Protein $(g / d)$ & 119 & 27 & 75 & 10 & 0.0 \\
\hline Protein (\% DV) & 19 & 2 & 18 & 2 & 0.5 \\
\hline Protein ( $\mathrm{g} / \mathrm{kg}$ body weight per $\mathrm{d}$ ) & $2 \cdot 2$ & 0.6 & 1.3 & 0.2 & 0.0 \\
\hline Lipids (g/d) & 82 & 20 & 63 & 9 & 0.0 \\
\hline Lipids (\% DV) & 29 & 5 & 34 & 4 & 0.012 \\
\hline
\end{tabular}

SBS, short bowel syndrome; CG, control group; DV, daily value.

* Participants without SBS were matched for characteristics similar to those of SBS participants including sex, age, ethnicity, BMl and chronic diseases. DV ${ }^{(28)}$. carbohydrate $45-65 \%$ of DV, protein $10-35 \%$ of DV, lipids $20-35 \%$ of DV. $\dagger$ Independent Student's $t$ test for comparison between SBS and CG groups.
Regarding the macronutrient distribution of the total EI, only the percentage of lipid intake was higher in the CG group $(P=0 \cdot 012)$ compared with the SBS group. However, macronutrient intake was within the recommendations ${ }^{(28)}$ for both groups. Protein consumption per kg of body weight per d was higher for patients in the SBS group $(P=0 \cdot 001)$.

EIrecall was compared with the TEEdlw in the groups (Fig. 1). The SBS group had a higher EIrecall (11.07 (SD 3.45) MJ/ d) in comparison with TEEdlw (7.85 (SD 1.16) MJ/d) $(P=0.014)$. However, the EIrecall $(7 \cdot 19(\mathrm{sD} 1.68) \mathrm{MJ} / \mathrm{d})$ was lower than the TEEdlw $(10.02(\mathrm{sD} 1 \cdot 86) \mathrm{MJ} / \mathrm{d})(P=0.001)$ in the CG.

\section{Discussion}

A significantly higher EIrecall was observed in SBS patients in comparison with measured TEE by the DLW method. This suggests that relying on self-reports alone in the long term can be mistaken for provision of adequate energy needs and can compromise nutritional status in SBS patients in whom malabsorption is highly prevalent. For most SBS patients, hyperphagia (defined as an oral intake greater than 1.5 times the $\operatorname{REE}^{(30)}$ ) is key to achieving body's energy demands and compensating for malabsorption $^{(30-32)}$. Therefore, increasing energy recommendations by an upward adjustment of the EIrecall may be warranted for SBS patients, as suggested by the findings from our study.

All SBS patients who can be maintained on an oral diet need to ingest more energy than normal individuals, as most of the dietary energy is poorly absorbed ${ }^{(33)}$. The literature indicates that patients with short bowel, who are clinically stable for at least one year, present a total fat, carbohydrate, protein and energy absorption in the order of $54,61,81$ and $62 \%$, respectively $^{(34)}$, and on average SBS patients absorb $52 \%$ of fats, $79 \%$ of carbohydrates, $61 \%$ of protein and $67 \%$ of total energy content ingested ${ }^{(35)}$. Considering that stable adult patients with SBS absorb only about one-half to two-thirds of the EI, energy prescriptions must be increased by at least $50 \%$ of the estimated energy needs ${ }^{(36,37)}$.

The observation of under-reporting of EI by subjects in the CG group who were weight stable before and during the study is similar to observations of under-reporting, which is commonly prevalent when intake is self-reported ${ }^{(38)}$. Further, the estimated dietary intake included $4 \mathrm{~d}$ of assessment, and was
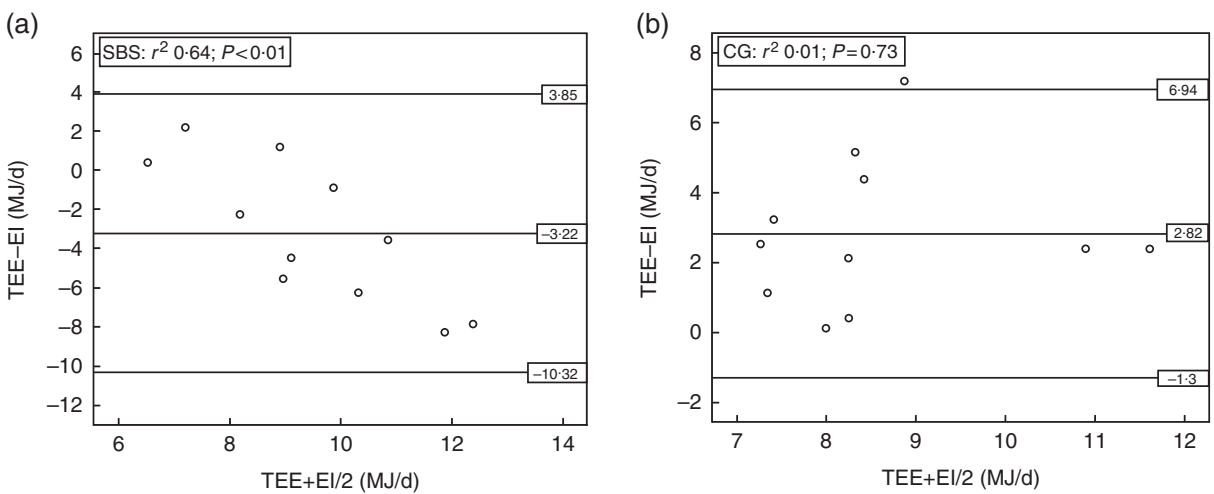

Fig. 1. Bland-Altman plots for comparison between self-reported 24-h energy intake (EI) v. measured total energy expenditure (TEE) in the groups with short bowel syndrome (SBS, $n$ 11) (a), and without short bowel syndrome (control group (CG), $n$ 11) (b). DLW, doubly labelled water. 
adjusted for intrapersonal and interpersonal variability. Usually, under-reporting is identified through the comparison between EI and TEE as measured by the DLW method, which is considered an excellent biomarker for $\mathrm{EI}^{(39)}$.

With regard to the distribution of macronutrients in the diet, both groups presented percentages of intake that were within the current recommendations ${ }^{(28)}$ (45-65\% of the energetic daily value for carbohydrate, $10-35 \%$ for protein and $20-35 \%$ for lipid), and only lipid intake was slightly lower in the SBS patients compared with the CG, suggesting that major changes to the macronutrient recommendations may not be required so long as energetic intake is adequately planned for. Therefore, for adult SBS patients requiring about $0.13 \mathrm{MJ} / \mathrm{kg}$ per $\mathrm{d}$, the energetic intake should be increased gradually, up to about $0.25 \mathrm{MJ} / \mathrm{kg}$ per $\mathrm{d}$, in order to promote hyperphagia, and facilitate sufficient absorption of energy content ${ }^{(31)}$.

Although we included all the SBS patients registered at our hospital during the past 18 years, the sample size is small and is a potential limitation of this study. However, given that SBS is a rare disease, we would not have been able to increase our sample size. Another potential limitation is that all the enrolled participants were from one centre; however, this is a primary centre that attends to patients who are referred from all around São Paulo state and from other states in Brazil. A second limitation is that we were unable to measure faecal energy losses in this population and future studies including this aspect, as well as conducting a provided food study where the patients are fed at the level of their reported EI, may help in elucidating the reasons for the discrepancy in REE $v$. measured EI. The strength of the study is that it is, to our knowledge, the first study comparing measured total daily energy expenditure with daily self-reported EI in adults with SBS and with extended survival after surgery.

\section{Conclusion}

In SBS patients, a hyperphagic diet is the key for achieving energy needs. Our study shows that self-reported EI does not reflect the energy available to the SBS patient, and could be misleading when used as the basis for providing or prescribing energetic intake for these patients. The long-term consequence of inadequate EI is the potential for impaired nutritional status and poor recovery from episodes of hospitalisation. Careful monitoring for the provision of additional intake by upward adjustment of self-reported intake to compensate for malabsorptive losses is highly recommended.

\section{Acknowledgements}

The authors wish to thank the São Paulo Research Foundation (FAPESP) for the financial support, grants nos 2012/22543-3 and 2012/22542-7.

P. G. F. and K. P. designed the research; P. G. F. conducted the research; J. S. M. and E. F. provided essential materials and support; P. G. F., K. P. and S. K. D. analysed data; P. G. F. and S. K. D. wrote the manuscript; and S. K. D., P. G. F., E. F., J. S. M., K. P. and V. M. M. S. had primary responsibility for the final content. All authors read and approved the final manuscript. None of the authors declared a conflict of interest.

\section{References}

1. Thompson JS, Rochling FA, Weseman RA, et al. (2012) Current management of short bowel syndrome. Curr Probl Surg $\mathbf{4 9}$, 52-115.

2. Fassini PG, Pfrimer K, Ferriolli E, et al. (2016) Assessment of energy requirements in patients with short bowel syndrome by using the doubly labeled water method. Am J Clin Nutr 103, 77-82.

3. O'Keefe SJD, Buchman AL, Fishbein TM, et al. (2006) Short bowel syndrome and intestinal failure: consensus definitions and overview. Clin Gastroenterol Hepatol 4, 6-10.

4. Thompson ABR, Chopra A, Clandinin MT, et al. (2012) Recent advances in small bowel diseases: part II. World J Gastroenterol 18, 3353-3374.

5. Drehmer M, Mello ED, Gazal CHA, et al. (2007) Manejo nutricional de pacientes com Síndrome do Intestino Curto (Nutritional management in short bowel syndrome). Rev Bras Nutr Clin 22, 174-180.

6. Jeppesen PB (2014) Spectrum of short bowel syndrome in adults: intestinal insufficiency to intestinal failure. JPEN $J$ Parenter Enteral Nutr 38, 8S-13S.

7. Kelly DG, Tappenden KA \& Winkler MF (2014) Short bowel syndrome: highlights of patient management, quality of life, and survival. JPEN J Parenter Enteral Nutr 38, 427-437.

8. Lochs H, Dejong C, Hammarqvist F, et al. (2006) ESPEN guidelines on enteral nutrition: gastroenterology. Clin Nutr 25, 260-274.

9. Hise ME, Sullivan DK, Jacobsen DJ, et al. (2002) Validation of energy intake measurements determined from observerrecorded food records and recall methods compared with the doubly labeled water method in overweight and obese individuals. Am J Clin Nutr 75, 263-267.

10. Redman LM, Kraus WE, Bhapkar M, et al. (2014) Energy requirements in nonobese men and women: results from CALERIE1-3. Am J Clin Nutr 99, 71-78.

11. Chagas Neto FA, Barreto ARF, Muglia VF, et al. (2011) Barium follow through in the assessment and follow-up of adult patients with short bowel syndrome. Radiol Bras 44, 188-191.

12. World Health Organization (1995) Physical status: the use and interpretation of anthropometry. Report of a WHO Expert Committee. World Health Organ Tech Rep Ser, no. 854, 1-452.

13. Compher C, Frankenfield D, Keim N, et al. (2006) Best practice methods to apply to measurement of resting metabolic rate in adults: a systematic review. J Am Diet Assoc 106, 881-906.

14. Fassini PG, Silvah JH, Lima CMM, et al. (2015) Indirect calorimetry: from expired $\mathrm{CO}_{2}$ production, inspired $\mathrm{O}_{2}$ consumption to energy equivalent. $J$ Obes Weight Loss Ther S5, $1-3$.

15. Weir JB (1949) New methods for calculating metabolic rate with special reference to protein metabolism. J Physiol 109, 1-9.

16. Frayn KN (1983) Calculation of substrate oxidation rates in vivo from gaseous exchange. J Appl Physiol 55, 628-634.

17. International Atomic Energy Agency (2009) Assessment of Body Composition and Total Energy Expenditure in Humans Using Stable Isotope Techniques. Vienna: IAEA.

18. Coward WA (1998) Contributions of the doubly labeled water method to studies of energy balance in the Third World. Am J Clin Nutr 68, 962S-969SS

19. Schoeller DA, Taylor PB \& Shay Y (1995) Analytic requirements for the doubly labeled water method. Obes Res 1, 15-20.

20. Colley RC, Byrne NM \& Hills AP (2007) Implications of the variability in time to isotopic equilibrium in the deuterium dilution technique. Eur J Clin Nutr 61, 1250-1255. 
21. Moshfegh AJ, Rhodes DG, Baer DJ, et al. (2008) The US Department of Agriculture Automated Multiple-Pass Method reduces bias in the collection of energy intakes. Am J Clin Nutr 88, 324-332.

22. Monteiro JP, Pfrimer K, Tremeschin MH, et al. (2007) Consumo alimentar - visualizando porções (Food Consumption - Viewing Portions). São Paulo: Guanabara Koogan (Nutrição e Metabolismo).

23. Tran KM, Johnson RK, Soultanakis RP, et al. (2000) In-person vs telephone-administered multiple-pass 24-hour recalls in woman: validation with doubly labeled water. J Am Diet Assoc 100, 777-783.

24. Pinheiro ABV, Lacerda EMA, Benzecry EH, et al. (2004) Tabela para avaliação de consumo alimentar em medidas caseiras (Table for Evaluation of Food Consumption in Home Measures), 5th ed. São Paulo: Atheneu.

25. Universidade Estadual de Campinas (2006) Núcleo de Estudos e Pesquisas em Alimentação (NEPA). Tabela Brasileira de Composição de Alimentos (TACO) (Nucleus of Studies and Food Research (NEPA). Brazilian Table of Food Composition (TACO)): Version II, 2nd ed. Campinas: NEPA-UNICAMP.

26. US Department of Agriculture \& Agricultural Research Service (1998) USDA nutrient database for standard reference. Release 12. https://ndb.nal.usda.gov/ndb/search (accessed November 2015).

27. Nusser SM, Carriquiry AL, Dodd KW, et al. (1996) A semiparametric transformation approach to estimating usual daily intake distributions. J Am Stat Assoc 91, 1440-1449.

28. Institute of Medicine (2005) DRI Dietary Reference Intakes for Energy, Carbohydrate, Fiber, Fat, Fatty Acids, Cholesterol, Protein and Amino Acids (Macronutrients). Washington, DC: National Academies Press. http://www.nap.edu/read/10490/ chapter/1 (accessed December 2015).

29. Black AE \& Cole TJ (2000) Within- and between-subject variation in energy expenditure measured by the doubly-labelled water technique: implications for validating reported dietary energy intake. Eur J Clin Nutr 54, 386-394.

30. Crenn P, Morin MC, Joly F, et al. (2004) Net digestive absorption and adaptive hyperphagia in adult short bowel patients. Gut 53, 1279-1286.

31. Jeejeebhoy KN (2014) Short bowel syndrome. In Modern Nutrition in Health and Disease, vol. 77 11th ed., pp. 1069-1079 [AC Ross, B Caballero, RJ Cousins, et al., editors]. Philadelphia, PA: Lippincott Williams \& Wilkins.

32. Matarese LE, O'Keefe SJ, Kandil HM, et al. (2005) Short bowel syndrome: clinical guidelines for nutrition management. Nutr Clin Pract 20, 493-502.

33. Nightingale J \& Woodward JM (2006) Small bowel nutrition committee of the British Society of Gastroenterology. Guidelines for management of patients with a short bowel. Gut $\mathbf{5 5}$, iv1-iv12.

34. Woolf GM, Miller C, Kurian R, et al. (1987) Nutritional absorption in short bowel syndrome. Evaluation of fluid, calorie, and divalent cation requirements. Dig Dis Sci 3, 8-15.

35. Messing B, Pigot $\mathrm{F}$, Rongie $\mathrm{M}$, et al. (1991) Intestinal absorption of free oral hyperalimentation in the very short bowel syndrome. Gastroenterology 100, 1502-1508.

36. Dibaise JK, Young RJ \& Vanderhoof JA (2004) Intestinal rehabilitation and the short bowel syndrome: part 2. Am J Gastroenterol 99, 1823-1832.

37. Parrish CR \& Dibaise JK (2014) Short bowel syndrome in adults - part 2: nutrition therapy for short bowel syndrome in the adult patient. Pract Gastroenterol 134, 40-51.

38. Karelis AD, Lavoie ME, Fontaine J, et al. (2010) Anthropometric, metabolic, dietary and psychosocial profiles of underreporters of energy intake: a doubly labeled water study among overweight/obese postmenopausal women - a Montreal Ottawa New Emerging Team study. Eur J Clin Nutr 64, 68-74.

39. Schoeller DA (2002) Validation of habitual energy intake. Public Health Nutr 5, 883-888. 